also point out that these are not fortuitous coinci- have been informed that it was probably one of the dences, because for two years at least before com- first on the subject sent to our military medical aumencing tabulation, this association was remarked. thorities since the War, I will reproduce it here, Furthermore, I asked my friend, Mr. Morant Baker, merely to introduce the remarks I am about to make to inquire for me about the prevalence of hip dis- on military first aid to the injured. I have never ease at the Evelina Hospital, which is largely used received any reply to the letter, not even an acby Jews. He tells me that few children are there knowledgment of its receipt, and it was probably admitted for hip disease, and that most of those so received belong not to Jewish, but to the Christian community. The important fact, however, is simply, coincidence of phimosis and hip disease-a coincidence which I should never have dreamed of or imagined, had it not been forced upon my observation. Upon the mode in which the one influences the other I would rather not speculate further than to point out that phimosed children have facile, frequent and often long.continued priapism; that this condition, unnatural in the infant, must produce after a time a certain irritability or irritation of the lumbar spinal cord; that from this part the various nerves of the pelvis and lower limbs are given off; that the influ. ence of spinal irritation on the trophic nerves is well known; and that just at this particular period large trophic changes are in progress about the hip juint." During the time that he was collecting these Ioo cases in boys, he met with 74 cases among girls. In a large proportion of them he found vulvitis, vaginitis, protruding nymphæ or nymphæ covered by a cuticular surface.

Dr. Sayre noticed this same coincidence, and connected the condition with hip.joint disease by the supposition that the majority of cases of this affection start from a fall or injury. The increased muscular debility from reflex irritation readily contributes to these falls.

Charcot, speaking of urinary paraplegia, says: "The very number of the cases in which we see paraplegia appear in the course of disease of the urinary passages is of itself enough to show that the phenomenon is no chance coincidence."

From the foregoing I think that we are justified in the conclusion that phimosis and adherent prepuce give rise to varied troubles of more or less gravity, manifesting themselves either in the muscular, osseous or nervous systems; and that the removal of these abnormal conditions of the penis frequently affords marked relief, and at times perfect and permanent cure.

\title{
THE IMPORTANCE FOR INSTRUCTION IN FIRST AID TO THE INJURED.
}

BY W. THORNTON PARKER, M.D. (MUNICH). OF NEWPORT, R. I.

LATE A, A, SURGEON U. S, ARMY, ignominiously pigeonholed:

\section{To the Medical Director Dep't of the Missouri :}

Sir:-I beg leave to call attention to the great success of the New York State Charities Association in organizing societies in various sections of the country for the purpose of affording instruction by lectures, illustrations, etc., in " First Aid to the Injured." The efforts have met with much general encouragement from the public, and their good effects have been recognized. It has occurred to me that it might be advisable to have something of this kind attempted at our military posts, providing suitable instruction in "first aid to the injured" to both officers and men. It undoubtedly frequently happens that officers in command of small detachments, deprived of the services of a surgeon, are called upon to extend aid to the sick and wounded, and although on more than one occasion officers have been found who were not only ready, but able to offer valuable assistance, yet a careful instruction in the course suggested would enable them to more fully afford relief and save considerable suffering. At all of our larger posts, and especially at $F$ ort Leavenworth, this course of instruction could be very easily carried out, and suitable appliances being already on hand, little if any expense would be incurred to illustrate the lectures. It is reasonable to believe that many officers and men woukd be interested in these lectures, and only good would result to the Army by a general distribution of the knowledge which may be able not only to alleviate suffering, but even to save life. Very respectfully, your obedient servant, W. ThOKNTON PARKER,

Ft. Gibson, Indian Ter., June 6, 1884 .

Act. Asst. Surgeon U. S. A.

It is possible, however, that the letter was referred from one office to another until at last it attracted some official notice in the War Depar!ment, and may have indirectly resulted in the promulgation of the following order, which must prove of considerable value to the Army in the near future:

General Orders, ?

No. 86.

The Secretary of War being of opinion that instruction by lecture or demonstration in the simpler practice of medicine and surgery may with advantage to all concerned be given by officers of the Medical Department stationed at military posts to other officers and the enlisted men serving thereat, directs that, whenever practicable and where voluntary attendance in sufficient numbers can be secured, arrangements be made for a series of such lectures on the practical treatment of the unhidden diseases, early ajd to the injured, the most expeditious and proper manner of treating temporarily gunshot wounds, poisoned wounds, frostbite, bruises, dislocations, hæmorrhage, and fractures of bones; application of the tourniquet; the most approved method for resuscitation from drowning; and other kindred subjects.

Medical officers delivering these lectures will forward, not later than June 30,1887 , through the regular military channels, to this office, a report of the results, beneficial or otherwise, which may have attended them up to that date.

By command of Lieutenant-General Sheridan :

\section{R. C. DRum, Adjutant-General.}

Whatever the fate of my communication to the Medical Director may have been, it is very gratifying for me to see that our military authorities are gradually awakening to what has been proven an absolute necessity in foreign armies. Probably in no other country has this matter secured the attention and won the success which has attended this humane and practical movement in England. 
One of the best appliances for ready use in first in the form of a cravat by rolling the point several aid to the injured is the Esmarch triangular bandage. times in the direction of the lower edge; the oftener This is a strip of cloth fifty inches long, triangular in it is folded the narrower the bandage becomes. Under shape, its greatest width being 24 inches. Upon the this form a practical bandage is made, not only for bandage are six pictures illustrating its use, and with wounds upon the neck, but also for those on many the band ige is a little book describing its use. For other portions of the body; for example, the eye, the benefit of thise who do not read French or Ger the forehead, the ears, the cheeks, the chin, and the man I have translated the directions and given the lower jaw. It is employed in the same manner for foreign address of the manufacturers, although I pre- thr sume that Messrs. Geo. Tiemann \& Co. can furnish the packet with English directions in any needed ! in quantity.

\section{Translation.}

FIRST AID TO THE IN JURED.

the simple muscular wounds of the extremities, and for fixing the splints and other protective apparatus in the case of fractured bones; besides making all of it, as a sling for supporting the wounded arm. The manner of employing the bandage under this form is so simple that no particular description is necessary. The ends are well fastened by means of

Under this title the undersigned Society offers to persons in every state and condition-in the work. shops, mamufactories, mines, and railroad organizations, engineering undertaking;, to all travelers and emigrants, and to any thoughiul family-an emergency packet for wound dressing, which. thanks to its small, compact form, its convenient arrangement and facility of packing, will give it a place everywhere; it can be carried under all circumstances. Each one of these packets is sold for one franc (fifty centimes) postpaid, and contains: First, a compress composed of cotton charpie of Dr. Bruns, and an antiseptic bandage. These two kinds of bandage have the property of absorbing the fluids, blood and pus, and protect the wound against hurtful influences. 2. Two bands of linen, one wide, the other straight, with pins for fastening them. 3. Some "ping-hawaryambi," as a hæmostatic application. 4. A triangular piece of linen prescribed by I)r. von Esmarch. With the aid of this apparatus the majority of bandaging operations may be accomplished withont any special skill. The method is as follows: The compress, which is folded in four, unfolds in such a manner that the cotton lint will be covered entirely by the bandage (antiseptic), which gives a surface similar in form to a sheet of letter-paper. We cut off each time the requisite quantity for covering the wound. After having washed the latter, and controlled the hæmorrhage by means of the application of the ping-hawaryambi, it is covered with a piece of the compress, which is fastened by means of the linen bandages, which, should the wound be upon the head, neck, trunk, or main parts of the extremities by the use of the triangular bandage (Esmarch's). If it be a case of an open or deep wound, you form with the compress a pad proportioned to the size of the wound, which is introduced therein after previously saturating it with good olive oil, if this be within reach. According to the abundance of the secretions from the wound, it will be necessary to change the bandage once or oftener during the day; in this case, the same bandage and the same linen can be employed-but it is important to renew the compress or the pad. As to the employment of the Esmarch's bandage, we will quote the words of Professor Esmarch, who, in his celebrated work entitled "The First Aid in Bandaging on the Field of Battle," expresses himself as follows:

"According to the part of the body wounded, the triangular bandage is used as follows: It is folded strong pins, or well knotted one with the other. For dressing a wound on the head, or a simple scalp wound, the bandage is placed upon the head in such a manner that the lower border will be brought directly across the forehead, the point hanging towards the neck. Then the two ends are passed backwards, behind the ears, turned again and tied in front. The point hanging in front is pulled down firmly, returned upon the head, and fastened on the top of the head with a pin (head bandage or cap).

"To bandage a wounded hand a small bandage is necessary. The hand is placed upon the opened bandage in such a manner that the wrist covers the middle of the lower edge, and the points of the fingers are directed to the pointed end of the bandage. The point is then turned backward over the hand in the direction of the forearm. The two remaining ends are crossed over the point of the bandage and tied on the other side of the wrist.

"For the foot the sole is placed on the middle of the bandage, so that the toes are directed towards the point. The point is then brought forward over the top of the foot and the two ends are passed around the malleolar processes, crossed on top of the foot and tied under the sole.

"We can also bandage the stump after amputation in the same manner. The superior border or biased edge is placed around the limb above the extremity of the stump, turned around the wound, the hanging point is brought up over the wound, and the two free ends are adjusted over these and tied.

"To comfortably sling or suspend a wounded arm the ends must be placed over the uninjured shoulder and upon the neck sufficiently in front so that it will readily pass around the neck to the other side, and it is there fastened, while the other end hangs in front of the body. We carefully place the bended arm upon the middle of the linen, advancing the point below the elbow several inches. Then the end which hangs before the arm is brought back to the side of the shoulder of the wounded arm and tied with the other end upon the back. Then the point is brought around the elbow and fastened with a pin. This bandage is called the large scarf or big sling bandage. "For bandaging wounds upon the chest the middle of the linen is placed upon the chest, the point raised and turned backward, pass ng over one shoulder, and the inferior border adjusted (at the waist) in the region where the chest and abdomen unite; then bring- 
ing the two ends backward and tying them together upon the back. The pointed end passed over the shoulder is then drawn down and made to pass under the knotted end, and adjusted by means of a pin or knot. For wounds on the back one proceeds in the same manner, but inversely. For wounds upon the shoulder the bandage is cut into two equal parts, of which one is folded in cravat form and is used as a little scarf for the forearm, whilst the other is placed upon the wounded shoulder in such a manner that the point shall be upon the side of the neck and the superior border upon the middle of the forearm. The ends are then passed around the under side of the arm, crossed beneath the point of the elbow, and tied together on the exterior surface of the forearm. The point of the bandage is then slipped under the scarf at the neck, plaited back upon itself and fastened with a pin at the top of the shoulder.

"In the same manner the bandage is placed upon the hip; and here we often need the entire bandage, because the upper part of the thigh is much larger than that of the arm. The inferior border of the bandage is passed around the largest part of the thigh, and the ends fastened with a double knot, but in the cases where the thigh is too large it is pinned. The point of the bandage is adjusted in the same manner as for the shoulder, by passing under the leather belt of the soldier, returned upon themselves and fastened with a pin. When there is no leather belt it will be necessary to use a second bandage folded in cravat form."

Everyone can be assured that in the manner detailed above our bandage outfit for wounds will prove satisfactory for first usage in the majority of cases of wounds. The essential thing, which is self-evident, is to have it constantly available, which is now easily accomplished, thanks to its available form. Consequently we recommend "our first aids" to all persons, as already mentioned. We recommend, also, to all large establishments, the packet containing the articles indicated as necessary to complete the outfit, which will be found invaluable when one has become accustomed to their use.

The International Manufactory of Bandaging Articles, at Schaffhausen, Switzerland. Articles to com plete our bandage packet: cotton-charpie of Dr. Braus in packages three-fourth, one-half and oneeighth $\mathrm{lb}$.; hydrophile bandage in packages of a yard and one-half to ten yards; triangular bandage with illustrations of wounded soldiers.

The two best works at present obtainable on this subject of ambulance corps organization are: first, "Manual for the Medical Staff Corps (British), War Office, I885. Official Copy." This is a most valuable little work, is very suitable for our own Army, and should be reproduced here. The second is "Ambulance Handbook for Volunteers and Others," by J. A. Raye, Surgeon, and is published by Churchill, London.

These books are very important, and their completeness and admirable arrangement make them invaluable additions to the surgical library. During the War (1863), Dr. Ordronaux published a valuable little work entitled "Hints on Health in Armies." It is for sale at present by Van Nostrand, I 92 Broadway, New York, and contains very valuable recommendations on military hygiene. Surgeon Woodhull's (U. S. A.) able article on "Military Hygiene," in the "Reference Handbook of the Medical Sciences," vol. iii, just published, contains the latest military medical science. I mention these writings on military hygiene because it is essential that they should be studied by all military surgeons, and because they contain valuable information for all medical men who are likely to have anything to do with military medical matters.

Three other works are in process of preparation or have been already published: Surgeon-General Langmore's work on "Transport, etc., of Sick and Wounded;" Surgeon Moore's "Manual of Drill for the Army Hospital Corps;" and Surgeon-Major Evatt's "Ambulance Organization Equipment and Transport." Another very important work in this connection, by Dr. Paul J. Möbius, Surgeon in the Saxon Army, entitled "Grundriss des Deutschen Militair-Sanitătswesens," has been translated, and will soon be published in this country, but in an abridged form.

This important subject has received comparatively little attention from the medical press, but the Boston Medical and Surgical Journal has done much to awaken interest in the matter, and from time to time valuable editorials and items have appeared in its columns. This has come about, no doubt, in consequence of the enterprise shown by the SurgeonGeneral's Office of Massachusetts, which has, without doubt, led in this matter, and has accomplished more in ambulance drill than all the organizations in the country.

The following editorial, in the Boston Medical and Surgical Journal of September 23, I884, is well worth reproducing, and should strongly appeal to any officers interested in this important branch of the military service :

"It is generally understood that a militia should be a school of instruction for the men, and the public expect the development of a nucleus from which can grow, in case of necessity, an effective body of soldiers. Now, it is a well-known axiom that familiarity and experience with any work are necessary for its best accomplishment; therefore the training of an ambulance bearer corps should form part of the duty of the volunteer militia. Properly instructed and drilled, this' body would form a unit from which might spring in time of need a service of the greatest importance."

Volunteer ambulance bearer corps have recently been instituted at the various military camps in England, and great success and popularity have attended the efforts of those who have had charge of this important undertaking. This has been attempted in our own country, especially in Massachusetts, but has so far been considered a failure. It must be expected that great difficulties will be encountered at first, but each trial faithfully made makes success in the end more certain. Development goes on slowly in healthy action-the militia system itself demon- 
strates this fact. During the War, when one would have supposed that the plan would have secured prompt encouragement, efforts to establish an ambulance corps failed, and a bill for this purpose perished in the Senate, having received the discouraging and utterly unsound endorsement of the Committee as "an impracticable measure at this time."

I quote again from the same journal: "Modern warfare has reached a stage of perfection in which results are rapidly accomplished, and this is undoubtedly due to the development of arms which can be used with rapidity and precision, the mobilization of troops, and their rapid and machine-like movements. Modern warfare has brought into use the railroads, telegraphs, massive steel cruisers, and new explosives. When we consider that with the improved Gatling and Nordenfelt ten-barrel guns a thousand shots can be fired in each minute, as was actually done in the Soudan, we see that a large number of combatants can be rapidly disabled. This increase in destructive power creates an increased necessity for means of caring for the injured. Unfortunately, however, military commanders have generally considered the care of the wounded as a minor consideration, and only in recent years has it dawned upon such officers that the certainty of good care in the event of misfortune develops in men an ésprit de corps second only to the accomplishment of victories. Again, the certainty of good care and attention, in case of injury, softens the anxiety of those who part with their loved ones for the national defense. This home feeling forms the foundation of the moral support on which commanders at times lean so heavily, and without which supplies of men and materials to carry on their campaigns would be wanting. The lamentable failure of men to receive proper medical care in the Crimea early drew attention to the defects of the old system of caring for the disabled. It was only when Letterman, in our Civil War, developed gradually an ambulance system (which at the close of the War was quite effective), that the necessity for sure, rapid, and effective treatment and transportation of injured combatants was properly appreciated. Many will remember the heart-rending tales of the needless suffering in transportation inflicted on our soldiers in the early part of the Civil War. Needless, because this exigency of warfare should have been foreseen and provided for.

"At Aldershot, a few weeks since, a detail of a hundred men, acting as wounded soldiers, were searched for at night, after a supposed battle, by the aid of an electric light carried by a bearer company of the army hospital corps, with all the paraphernalia of transports complete. The application of the electric light was a distinct success, the necessary dressings of the wounded being performed with accuracy and dispatch.

"An attempt was made at one of the recent annual encampments of the Massachusetts militia to instruct the men in the treatment of emergencies; owing, however, to a variety of causes the trial was a failure. This was due, in a great measure, to the amount of tactical instruction and drill required of the men. The topics considered were of general interest, but the men showed a lack of appreciation because of these conflicting duties. It was also found impossible after "retreat," the men requiring amusement at that time rather than instruction and hard work. Now, while a general knowledge of the principles of sanitary science, as taught German officers, is of importance, we feel that in time of war the rapid treatment of wounded combatants demands the training of brave and intelligent men for this important work. We hope that there will soon be an ambulance bearer corps connected with the various State militias, under the control of the Surgeon-General of the State. A company should be connected with each brigade, under the direction of the medical director, and this company should be composed of enlisted men, having the proper number of sergeants, corporals, and privates. A number of such a bearer corps should be medical students, as it is self-evident that by the discipline of such a service they would be better fitted to act after graduation as medical officers of the volunteer militia.

"Major-General George B. McClellan appreciated the necessity for an ambulance corps. In a letter dated February 2 I, I $86_{3}$, addressed to Henry I. Bowditch, M.D., in answer to the question, "Should the men in the ambulance corps be detailed soldiers, taken from time to time from the ranks, or should they be men enlisted for the purpose and taught their especial duties?' General McClellan answered as follows: 'There are many self-evident objections to the system of taking men temporarily from the ranks for this duty; they need instructions in their peculiar functions as well as the ordinary discipline, and should have distinctive uniforms. I am of the opinion that men should be enlisted especially for duty in the ambulance corps.' Dr. Bowditch asked also the following question: 'Do you think the establishment of such a corps would increase the the number of non-combatants?' McClellan's answer is: "I think it would decrease the number of non-combatants, especially during battles."

Besides the evident value of preparing soldiers to administer intelligently first aid to the injured, some effort should be made to instruct train hands in this necessary work. "Every guard's van of every passenger train should carry a stretcher and a basket of bandages and restoratives. Every railway station should have a stretcher as part of its equipment; and every 'break-down' train sent to aid at accidents should include a regular sick transport wagon, containing dressings, restoratives and stretchers." Our recent frightful railway accidents prove this clearly.

It has been the purpose of this paper merely to act as a skirmisher in the great battle which must sooner or later take place, to decide what is useful and practical for the soldier's welfare, and what should be discarded. Prominent army officers are very apt to be conservative, and really important inventions are often put aside because they interfere with the old romantic ideas of generations past.

The object of this paper has been attained if I have emphasized the importance of "First Aid to the Injured," which in military life must develop into organized ambulance and stretcher corps. 
The books I have mentioned will give more information on the subject than any others yet seen by me. The English books especially are of the greatest value, and for those medical officers of our regular and volunteer army who are about to carry out the provisions of the general order referred to will be found of remarkable assistance and practical usefulness. The subject is of national importance, and unites with the highest humanity practical economy of human lives. There should be no delay in organizing for such an important movement in the history of the U. S. Army.

Newport, R. I., February 22, 1887 .

\section{BIBLIOGRAPHY.}

Hints on Health in Armies-for the use of Volunteer Officers. John Ordronaux, M. I). D. Van Nostrand, Publisher, New York. Manual for the Medical Staff Corps, Official Copy, War Of fice, I885. W. Clowes \& Sons, Charing Cross.

Ambulance Handbook for Volunteers and Others. J. Anderson Raye, Surgeon L. I. Rifles. J. \& A. Churchill, London. Grundriss des Deutschen Militair Sanitatwesens. By Paul J. Möbius, Asst. Surgeon Royal Saxon Sanitäts-Corps.

Reference Handbook of the Medical Sciences. Wm. Wood \& Co. Surgeon A. A. Woodhull, U. S. A., article on Military Hygiene.

L Dr. Porter's Surgeon's Handbook.

\section{REMARKS ON CATARACT EXTRACTION.}

\author{
Read before the Medical Society of the District of Columbia, \\ $\mathrm{Fel} .23,1887$.
}

BY SWAN M. BURNETT, M.D.,

PROPZSSOR OF OHH CHALMOLOGY ANU O RULOGY IN THE UNIVERSITY OF CERTETOWN, OPHTHALMIC AND AURAI SURGEON TO THE GARFIELD HOSPITAL; DIRECTOR OF THE OPHTHALMIC AND AURAL CLINIC AT THE CENTRAL DISPENSARY AND EMERGENCY HOSPITAL, WASH INGTON, D. C.

Since the opening of the Garfield Memorial Hospital about two years ago, I have made twenty-five extractions of senile cataract. The number is not large, but the cases have been of such a character as will very properly serve as a basis for a few remarks on some of the mooted questions concerning this most important surgical operation.

The extraction in every case was effected through an upward incision in the cornea, made in accordance with the plan of De Wecker; that is, the upper third of the cornea was detached from the sclerotic, the incision lying wholly in the transparent tissue. Sometimes a flap of less magnitude was formed by the apex of the incision lying farther from the scleral border than the base, but this was only exceptional, and experience shows that it has no essential advantages over the incision as perfected by De Wecker and now very largely adopted by operators who have not originated some special plan of their own. In no case was the incision placed so peripherally as in the method introduced by Von Gräfe.

This incision of De Wecker seems to steer us as safely through the straits between the Scylla of corneal suppuration, and the Charybdis of iritis and cyclitis as could be reasonably hoped for. It gives an opening sufficiently large for the easy delivery of even the largest nucleus, and the lips of the wound adapt themselves as perfectly and with as little danger of gaping as in the so-called linear incision of Gräfe. This in- cision offers yet additional advantages over the Gräfe linear, in that it enables us to make the extraction without an iridectomy. It seems therefore, that as far as the form and position of the incision are concerned, it is hardly possible for us to go farther towards perfection.

In ten of the cases the extraction was made without an iridectomy. This method, practiced largely, indeed almost without exception by the French, is struggling for a foothold in this country, with how. ever, I believe but only a moderate chance for immediate adoption. Certainly an eye with a central movable pupil is on all accounts to be preferred to one with a large coloboma in the iris, but it is equally certain that even in the hands of the most skillful this is not to be attained in all cases in operating without an iridectomy. In a rather large minority there will be prolapse of the iris. It is an operation demanding rather more skill in its performance and requiring more quiet and repose on the part of the patient for the first forty-eight hours after the operation than with an iridectomy. And yet it is an operation that I think should be cultivated, because I believe we shall in time be able to master most of its disadvantages. I attempt it in every case in which there is no marked increase in the tension of the eye-ball, and when the anterior chamber is reasonably deep. Under these conditions, with a moderately docile patient, I do not greatly fear a prolapsus of the iris. And, moreover, should the iris refuse to return after the delivery of the lens, with a moderate amount of coaxing, it is as easy to make excision of the iris after as before the exit of the lens, thus converting it into an ordinary extraction with an iridectomy. I do not find that delivery of the lens is any more difficult than with iridectomy, and I believe the danger of prolapse of the vitreous is less, since there is not so great a liability to rupture of the zonula.

The possibility, however, of prolapse of the iris after it has been once returned cannot always be guarded against, even by the use of eserine. Here eveything depends upon the accurate coöperation of the wound, and an early and persistent adhesion of its lips. A perfectly proper incision is therefore one of the first requisites for success in this method. This comes of skill and experience; but the second requisite-perfect rest of the eye for forty-eight hours-can never be counted on; for even the quietest patient, during sleep may make a sudden movement of the eye which will open the wound, when the aqueous humor will gush out, carrying with it the iris which remains thereafter fixed in the wound.

In two cases extraction was made with the lens in its capsule. In these cases an iridectomy was first made, since extraction in the capsule is much easier thus than with the iris entire. In both cases the result was perfect, and there was no escape of vitreous following the exit of the lens. In one instance it was done on account of a thickened and tough capsule; the other case was one of "black" cataract and it was desirable, for the purposes of investigation, to remove the lens in the capsule. ${ }^{1}$

${ }^{1} \mathrm{~A}$ detailed history of this case and a consideration of the subject of black cataracts ard the ir diagnosis is to be found in a clinical lecture published in the Medical News, Jan. 29, 1887 . 